\title{
0 público e o privado nas redes sociais: algumas reflexões segundo Zygmunt Bauman
}

\author{
Cristiane Koehler* \\ Marie Jane Soares Carvalho**
}

\section{Resumo}

Este artigo foi escrito a partir das reflexões realizadas com base na leitura das obras do sociólogo Zygmunt Bauman, que foram propostas em disciplina de curso de pós-graduação. As leituras foram realizadas individualmente, e as discussões foram feitas com o grupo de colegas, em momentos presenciais na sala de aula e em momentos à distância e online, mediados pela rede social Facebook. O objetivo deste artigo é apresentar as principais ideias discutidas sobre os conceitos do que é público e privado e relacioná-los com o conceito de privacidade e com o comportamento da geração digital, no contexto das redes sociais na cibercultura.

Palavras-chave: Modernidade líquida. Público. Privado. Redes sociais. Cibercultura.

\section{Introdução}

O objetivo deste texto é apresentar algumas reflexões e interlocuções entre as obras do sociólogo polonês Zygmunt Bauman, quanto aos conceitos de público e privado e suas relações com o conceito de privacidade no contexto das redes sociais na cibercultura. Esses estudos foram realizados nas leituras dirigidas intituladas "Modernidade líquida" e "Modernidade líquida II", oferecidas pela Professora Dra. Marie Jane Soares de Carvalho, no Programa de Pós-Graduação em Informática na Educação (PGIE), da Universidade Federal do Rio Grande do Sul (UFRGS), durante o ano letivo de 2012.

Para iniciar as reflexões, buscou-se analisar uma obra cinematográfica de ficção científica que pudesse oferecer subsídios concretos para refletir sobre os concei-

Recebido: 30/03/2013 - Aprovado: 27/05/2013

http://dx.doi.org/10.5335/rep.2013.3555

Mestra em Ciência da Computação (UFSC), Doutoranda no Programa de Pós-Graduação em Informática na Educação (PGIE), Universidade Federal do Rio Grande do Sul (UFRGS). E-mail: cristiane.koehler@ufrgs.br.

* Pós-Doutora (UNED-Madrid), Doutora em Educação (UFRGS), Professora da Faculdade de Educação (FACED) do Programa de Pós-Graduação em Educação (PPGEDU) e do Programa de Pós-Graduação em Informática na Educação (PGIE), Universidade Federal do Rio Grande do Sul (UFRGS). E-mail: marie.jane@ufrgs.br. 
tos estudados na disciplina e relacioná-los com o filme. A partir da escolha do filme, essas reflexões puderam ser elaboradas e discutidas no grande grupo de colegas da disciplina. O filme escolhido foi Violação de privacidade (The final cut). ${ }^{1}$

Escrito e dirigido por Omar Naim e estrelado por Robin Williams em 2004, esse filme tem como tema central a implantação de microchips no cérebro de algumas pessoas, os quais registram todos os momentos de sua vida. Os chips comercializados como Zoe Chips - são removidos após a morte do seu portador e as imagens, editadas por um especialista - o editor. Esse profissional tem como responsabilidade editar as memórias e lembranças registradas no chip, visando à produção de um filme que será exibido durante a cerimônia do funeral. $\mathrm{O}$ personagem vivido por Robin Williams é um dos maiores especialistas nesse tipo de edição, selecionando imagens que transformam as memórias da pessoa falecida em histórias imaculadas, livres de pecados, dissabores, violências ou aspectos que poderiam denegrir suas imagens.

A escolha desse filme foi feita considerando a identificação dos conceitos estudados a partir das obras de Zygmunt Bauman, que poderiam ser analisados com base na sua teoria. Para iniciar a análise da obra cinematográfica, destacaram-se algumas palavras-chave para o estudo: ciborg (HARAWAY, 1991, p. 62), chip, edição, subjetividade, representação, imagem, leitura, ética, público e privado. Em seguida, foram identificados os conceitos de público e privado, para serem analisados à luz das obras de Zygmunt Bauman.

No filme, os chips são fabricados por uma empresa denominada Zoe Tech, possivelmente fazendo alusão à combinação entre o humano e a máquina, ou, nesse caso, à prótese como "a parte ciber do corpo [...] que suplementa alguma deficiência ou fragilidade do orgânico ou que aumenta o poder potencial do corpo" (SANTAELLA, 2004, p. 187). Curiosamente, parece que o nome da empresa fabricante dos chips implantados nas personagens do filme não foi escolhido de modo aleatório, se for considerado o que afirma Agamben (1999): atualmente, estamos vivendo um estado de exceção, em que a distinção entre vida natural (zoe) e vida política (bios) não é mais tão clara como costumava ser.

Os portadores do chip Zoe podem ser entendidos como seres híbridos, conforme a descrição de Tucherman (2001), exatamente porque, desconhecendo que possuem implantes de chips registrando suas memórias, esses ciborgues escapam das fronteiras lógicas que balizamos para viver e pensar.

Analisando o enredo, compreende-se que os conceitos de edição e editor ocupam uma posição importante e central nas reflexões, em virtude da noção de ação associada a isso, pois é na interpretação do editor e em seu olhar que se baseiam as escolhas feitas na leitura para a construção dos filmes, retratando as memórias dos 
portadores dos chips. Da mesma forma, este texto é construído a partir do olhar das autoras que elegeram os conceitos público e privado que se integram na evolução do filme. Nesse sentido, é possível colocar-se no papel de editor, ao fazer a escolha do conceito e a interpretação com base teórica da área do conhecimento da computação e informática, mas que está unificada e integrada a um sistema complexo e macro de todos os conceitos que se expressam no filme.

A partir da escolha dos conceitos de público e privado, foi realizada uma pesquisa bibliográfica centrada nessas palavras-chave, que foram analisadas a partir da narrativa do filme. Esse é um simulacro do que o homem pode idealizar em sua ação com a máquina. Assim, com o uso de tecnologias, como máquinas fotográficas, filmadoras, ou, como propõe o filme, um chip implantado em uma pessoa, é possível saber todas as experiências vividas, sejam boas ou não.

Com o objetivo de sistematizar as discussões, organizou-se um mapa conceitual, utilizando o CmapTools ${ }^{\circledR 2}$ (software livre para a edição de mapas conceituais), que foi o norteador para as reflexões em questão. A Figura 1 mostra esse mapa conceitual com todos os conceitos identificados no filme e apresenta a ideia de que a edição invade o que é público e privado.

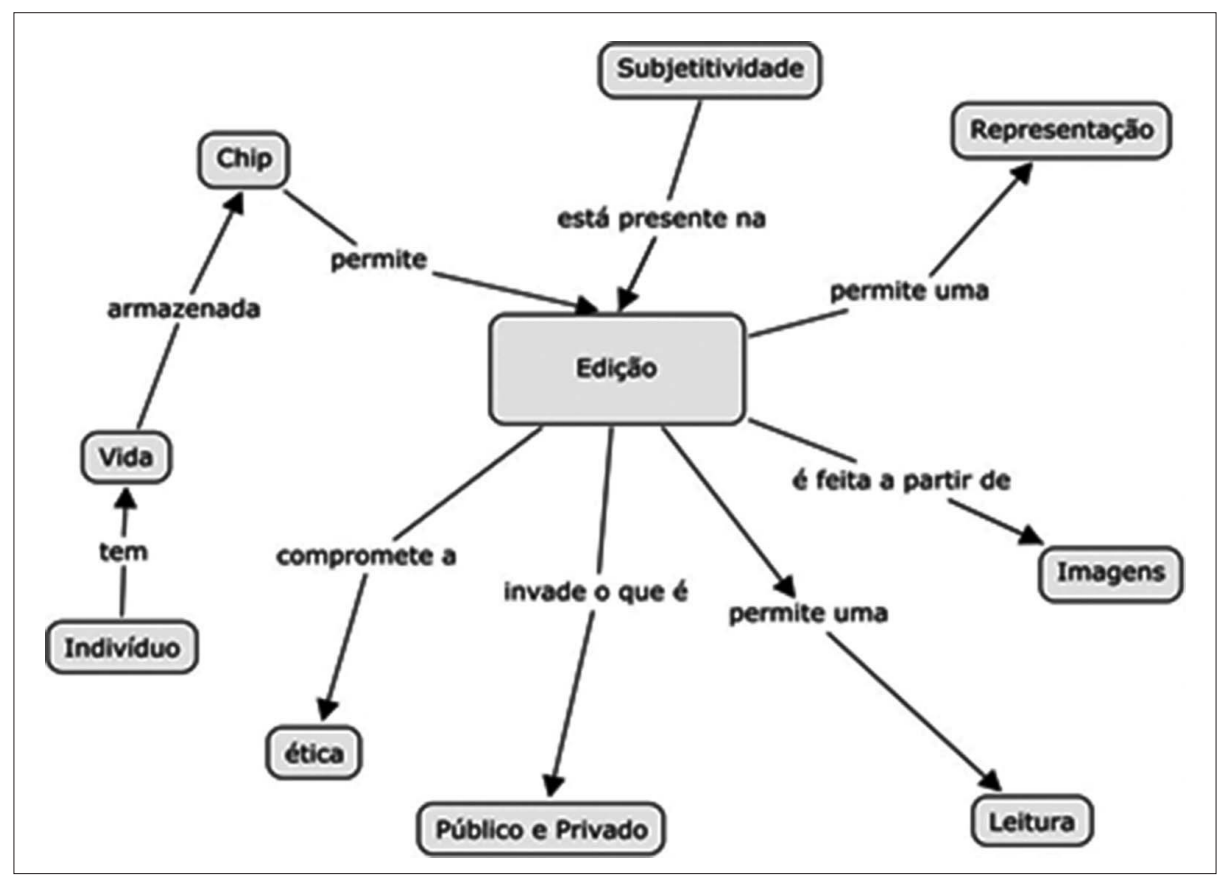

Figura 1 - Mapa conceitual relacionando os conceitos encontrados no filme 
Isso nos leva a associar a viabilidade de um chip que pode filmar ou gravar a vida "vivida", sendo depois possível construí-la ou reconstruí-la a partir do processo de edição realizado por uma pessoa externa, como um exemplo do que Lévy (2009, p. 24-5) propõe como movimento de virtualização. $\mathrm{O}$ autor descreve esse movimento como o "Efeito Moebius, ou a inversão entre externo e interno, privado e público, próprio e comum". Lévy desmistifica a oposição entre o real e o virtual. Para ele, a virtualização não se dá apenas dentro de máquinas computacionais. $\mathrm{O}$ virtual existe de forma potencial, pois, "quando uma pessoa, uma coletividade, um ato, uma informação se virtualizam, eles se tornam 'não presentes', se desterritorializam" (2009, p. 21). É nesse contexto que o filme aponta-nos a possibilidade de a vida de uma pessoa ser editada por um terceiro, passando essa edição pela subjetividade do olhar do editor em sua "especialidade profissional", que é selecionar e decidir o que será "publicado" da vida do outro no memorial que está sob sua responsabilidade.

Em seguida, realizou-se uma pesquisa bibliográfica, para discutir os conceitos de público e privado, relacionando-os com o conceito de privacidade nas redes sociais, com base nas obras de Zygmunt Bauman, discutidas em sala de aula presencial, e também, com a turma, em um grupo fechado da disciplina, organizado na rede social Facebook ${ }^{3}$.

A estrutura deste artigo apresenta, na segunda seção, uma reflexão sobre o conceito de redes sociais no ciberespaço e, na terceira seção, os conceitos de público, privado e privacidade nas redes sociais.

\section{As redes sociais e o ciberespaço}

O conceito de redes tem sido formulado em diferentes áreas do conhecimento, empregando metáforas que lembram encadeamentos, interações, associações, vínculos não lineares, todos envolvendo relações de comunicação de informações. Segundo Aguiar (2007), os diversos padrões de formação de redes de indivíduos e grupos sociais começaram a ser estudados a partir da década de 1940, sobretudo por sociólogos, antropólogos e psicólogos sociais dos EUA, da Inglaterra e da Alemanha (BARNES, 1972; ROGERS; KINCAID, 1981; SCOTT, 1992 apud AGUIAR, 2002), que utilizaram diferentes metáforas (malha, trama, árvore, teia) para descrever os padrões de conexão e de fluxo de informações entre os nós, até chegar à complexidade de um rizoma (DELEUZE; GUATTARI, 1996 apud AGUIAR, 2002).

No Brasil, as redes sociais passaram a despertar interesse acadêmico nos anos 1990, nas pesquisas sobre novas formas associativas e organizativas que emergiram dos processos de resistência à ditadura militar, de redemocratização do país, de globalização da economia e de proposição do desenvolvimento sustentável (AGUIAR, 2006, 2007). Para Marteleto (2010), redes sociais é um conceito onipresente nos dias 
de hoje e ocupa espaço crescente no discurso acadêmico, nas mídias, nas organizações ou no senso comum. Elas servem para dois fins. Primeiro, organizar o espaço de comunicação e interação no mundo globalizado e interconectado, no qual se produzem formas diferentes de ações coletivas, de expressão de identidades, de conhecimentos e de informações. Segundo, mostrar mudanças no modo de comunicação e interação entre as pessoas, na maneira como elas se socializam, se conhecem, como aprendem, escrevem e como forma de fonte do conhecimento globalizado.

Pode-se observar que as redes sociais representam as relações entre pessoas, que podem estar interagindo por interesse próprio ou em nome de uma instituição, mediadas ou não por computador. Observa-se, também, que as redes sociais são formadas com objetivos específicos, isto é, por pessoas que articulam outras pessoas em torno de interesses, projetos e objetivos comuns.

\section{0 público e o privado nas redes sociais}

A Figura 2, selecionada do filme Violação de privacidade, para representar o público e privado, mostra o editor sendo agredido pela população após manifestações contra os implantes de chip em bebês recém-nascidos, chamados de implantes Zoe. Esses protestos acontecem pelo fato de o editor mascarar a realidade, selecionando apenas as imagens que considera as mais adequadas, as politicamente corretas e felizes, para montar a rememória.

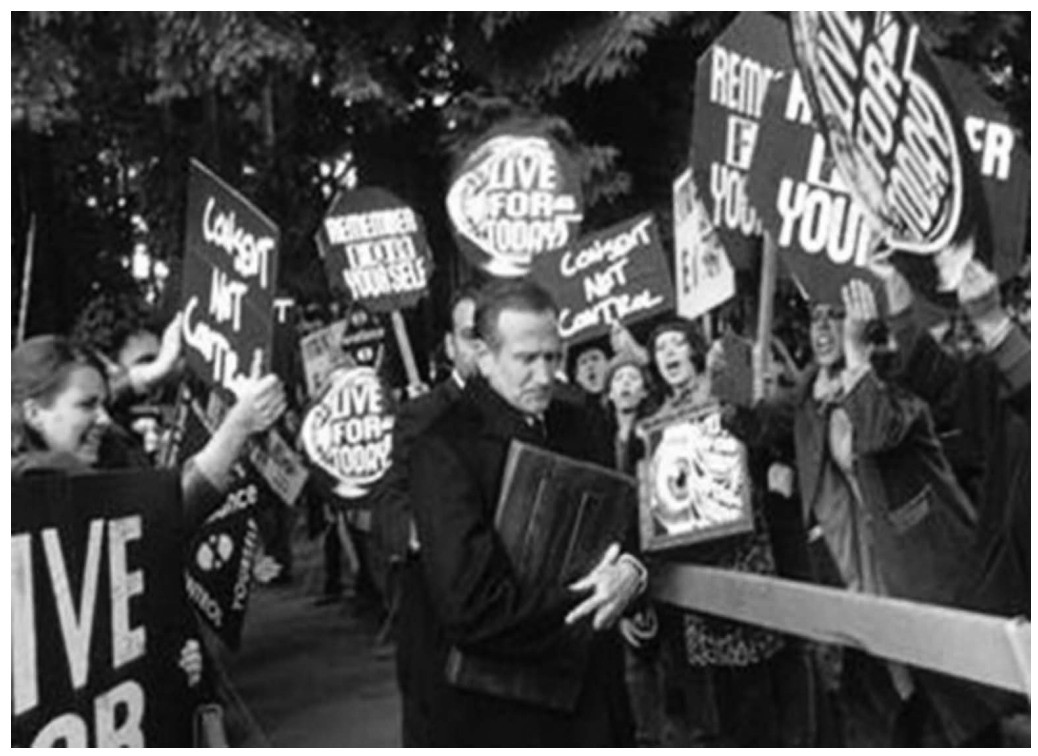

Figura 2 - Imagem do filme Violação de privacidade (2004) 
No contexto da obra cinematográfica, a questão do que é público e do que é privado consiste em refletir sobre até que ponto o editor ou a própria família tem o direito de mostrar, na esfera pública, parte da vida privada, até então considerada como parte íntima do falecido. E por que usar uma ferramenta de edição para mostrar apenas o que é politicamente correto, bonito, feliz e aceitável publicamente?

No entanto, é importante questionar-se sobre o que, realmente, é da ordem do privado. Sabe-se que o privado corresponde a algo que pertence ao domínio da privacidade e, consequentemente, a tudo o que não é público. Segundo o dicionário Aurélio, privacidade é a habilidade de uma pessoa em controlar a exposição e a disponibilidade de informações acerca de si. Relaciona-se com a capacidade de existir na sociedade de forma anônima. No caso do filme em questão, o falecido não tem ingerência sobre as suas memórias, simplesmente pelo fato de não saber que é portador de um implante Zoe e, assim sendo, não tem como gerenciar essa situação, tampouco solicitar edições do filme da sua vida privada para torná-la pública.

No contexto das redes sociais, amplamente utilizadas pela nova geração, chamada de geração digital (TAPSCOTT, 2010), a questão do que é público e do que é privado está em discussão no cenário escolar e preocupa pais e professores. Isso porque mais de cinco milhões de estudantes brasileiros já pertencem a uma rede social na internet, como o Facebook ou o Twitter ${ }^{4}$. As redes sociais na internet fazem parte da vida da geração digital. No entanto, sabe-se que tudo tem seu lado positivo, mas também seu lado negativo.

O positivo é que a participação ativa nas redes sociais está colaborando na preparação dessa geração para os desafios da economia digital, que requer habilidades de pensamento completamente diferentes do que era necessário na era industrial (CASTELLS, 1999). O sociólogo polonês Zygmunt Bauman (2012), também, apresenta reflexões importantes sobre o mundo pós-moderno e a condição social na qual estamos inseridos e que tem relação com o fato de não vivermos mais na era industrial, e sim na era do conhecimento:

O que aconteceu no século XX foi uma passagem de toda uma era da história mundial, ou seja, da sociedade de produção para a sociedade de consumo. Por outro lado, houve os processos de fragmentação da vida humana. [...]. No início deste século, as pessoas se preocupavam com o projeto de vida, e em executá-lo, passo a passo. Nos dias atuais, isto não acontece, porque a vida é dividida em episódios, fragmentados, o que não era assim no início do século XX. As sociedades foram individualizadas. Em vez de se pensar em termos de a qual comunidade se pertence, a qual nação se pertence, a qual movimento político se pertence, etc., tentamos redefinir o significado de vida, o propósito de vida, a felicidade na vida, para o que está acontecendo com a própria pessoa, as questões da identidade que têm um papel importante hoje, no mundo. A pessoa tem que criar a sua própria identidade. A pessoa não a herda. Não apenas é necessário fazer isso desde o início da vida, mas é necessário passar a vida, de fato, redefinindo a própria identidade. [...]. Muitas mudanças, não apenas a passagem do totalitarismo para a democracia, mas muitas outras coisas mudaram (BAUMAN, 2012). 
Desde as últimas décadas do século XX, estamos assistindo a diversas, rápidas, amplas e profundas transformações sociais, econômicas, culturais em âmbito mundial. Conforme as nomenclaturas propostas nos textos desenvolvidos por Bauman (1999, 2001, 2010, 2011, 2012), estamos passando da chamada modernidade sólida para a modernidade líquida. A modernidade sólida, segundo ele, derretia os sólidos para colocar outros melhores em seus lugares. Essas substituições terminariam quando os sólidos ali substituídos não tivessem mais problemas, atingindo, assim, a perfeição. A modernidade líquida derreteu tudo o que era ou parecia ser sólido, mas não coloca outro sólido em seu lugar. Assim, tem-se a constante mudança, num processo sem previsão de terminar.

A impermanência das coisas torna-se a única constante da modernidade líquida. "Os sólidos suprimem o tempo; para os líquidos, ao contrário, o tempo é que importa” (BAUMAN, 2001, p. 8 apud VEIGA-NETO; SARAIVA, 2009, p. 188).

As ideias de Bauman servem-nos de subsídios para compreendermos, em parte, as mudanças sociais que vivemos nas últimas décadas. Essas alterações aconteceram, rápida e significativamente, num amplo conjunto de práticas da sociedade pós-moderna que envolvem conhecimentos em diversas áreas: cultura, economia, política, ética, estética, educação, dentre outras.

Considerando as ideias apresentadas por Bauman, na área da educação, o lado negativo de todas essas transformações é a exposição da vida privada da geração digital nas redes sociais, por meio de fotos, comentários, vídeos, dentre outros, completamente sem critérios. Nesse sentido, a preocupação de pais e professores está relacionada a "o que" os estudantes compartilham nas redes sociais, pois, muitas vezes, são informações do âmbito privado que estão sendo disponibilizadas na esfera pública.

A discussão em torno dos conceitos do que é público e privado é importante, tendo em vista que se percebe que a sociedade pós-moderna, na qual estamos inseridos, vive o momento da modernidade líquida (BAUMAN, 2010), onde tudo é passageiro, efêmero e muda de forma rápida, sob a menor pressão. Na verdade, a geração digital é incapaz de manter a mesma forma por muito tempo. Então, o que hoje é privado amanhã passa a ser público e vice-versa. Porém, como decidir o que pode tornar-se público ou o que deve manter-se privado? O impulso para transgredir, substituir, trocar, acelerar não permite a solidificação das coisas.

Outra preocupação dos educadores está relacionada com o chamado enfraquecimento das relações humanas (BAUMAN, 1999), quando se observa que a quantidade de amigos nas redes sociais aumenta a cada dia. No entanto, da mesma forma que esse número aumenta, ficou mais fácil e rápido excluir dessa rede um amigo que já não é mais tão querido. 
Pode-se observar que as escolas que estão aderindo ao uso das redes sociais têm preferência pelo microblog Twitter, simplesmente pelo fato de preservar, ao menos em parte, a privacidade dos estudantes. Outra preocupação pertinente no uso das redes sociais é de ordem pedagógica, no que diz respeito ao tipo de linguagem que os estudantes tendem a usar na rede, bem distante da norma culta. Não é fácil estimulá-los a empregar o bom português nesse contexto, mas é imprescindível que pais e professores estejam atentos, lembrando sempre a importância da linguagem escrita de forma correta, mesmo nas redes sociais.

Levando em conta que o grau de exposição da informação privada depende de como o público a receberá, o que varia segundo lugares e épocas, o esforço para manter um assunto privado e a decisão de torná-lo público são objetivos antagônicos. As definições de privacidade e publicidade opõem-se. Privado e público são conceitos antagônicos:

Em geral, seus campos semânticos não estão separados por limites que permitam o tráfego de mão dupla, mas por fronteiras demarcadas: linhas intransponíveis, de preferência fechadas com rigidez e pesadamente fortificadas de ambos os lados para impedir transgressões, isto é, que se evite passar da esfera pública para a esfera privada com muita facilidade. Parece-nos que a crise atual da privacidade está bastante ligada ao enfraquecimento, à desintegração e à decadência de todas as relações humanas. Nesse processo, é muito difícil perceber quem veio antes, se a crise atual da privacidade ou a desintegração das relações humanas (BAUMAN, 2011, p. 43).

Para finalizar esta seção, é importante ressaltar que as reflexões sobre o que realmente deve se manter no âmbito privado e o que pode ser compartilhado na esfera pública precisam estar presentes tanto no contexto familiar quanto nas salas de aula. Com isso, espera-se que se consiga orientar os nossos filhos e estudantes para uma exposição, ou não, com responsabilidade.

\section{Considerações finais}

As redes sociais têm sido amplamente utilizadas entre a geração digital. Essas ferramentas de comunicação aproximam as pessoas, inicialmente, motivadas pela diversão e pela possibilidade de compartilhamento de fotos e mensagens. No entanto, constata-se que o seu uso na educação tem benefícios que podem ser observados em pesquisas científicas e trabalhos acadêmicos.

Muitas escolas já usam as redes sociais como aliadas na preparação dos estudantes e na comunicação entre a comunidade acadêmica, criando, inclusive, sites próprios para conectá-los. No entanto, muitas pessoas costumam considerá-las inimigas dos estudos. 
Toda mudança de comportamento na sociedade tem os seus prós e contras. Da mesma forma que aproximam, facilitam e agilizam a comunicação entre os estudantes, educadores e amigos, as redes sociais são utilizadas indiscriminadamente, sobretudo, pelos mais jovens que pertencem à chamada geração digital.

Observa-se que esses jovens não se preocupam com o conteúdo das mensagens nas redes sociais, e, da mesma forma, com muita facilidade adicionam "muitos amigos" aos seus perfis, excluindo de suas listas, com mais facilidade ainda, os que já não são tão queridos. Isso nos faz pensar no momento histórico que estamos vivendo, no qual tudo é descartável em nossas vidas, de objetos a pessoas e instituições, caracterizando a liquidez da sociedade pós-moderna.

Outro ponto importante a ser considerado é a exposição dos jovens nas redes sociais, feita muitas vezes sem critério algum do que pode ser compartilhado ou não. Por isso, é essencial que pais e educadores os orientem para o uso criterioso das redes sociais, a fim de protegê-los dessa exposição inadequada e de auxiliá-los a fazer o uso pedagógico dessas ferramentas.

Outro ponto negativo das redes sociais é o seu uso indevido pela imprensa sensacionalista, que publica fotos e informações privadas de pessoas públicas, as chamadas celebridades. Isso mostra uma preocupação a ser considerada no momento em que informações do âmbito privado transformam-se em públicas e notórias, o que acontece pela má utilização da internet e das redes sociais.

Inevitavelmente, tudo gira em torno da devida conscientização da geração digital para o uso adequado das novas tecnologias. Essa questão da conscientização não se resume ao fato de "os fins justificarem os meios", como afirmava Maquiavel no seu livro intitulado $O$ príncipe, mas na construção de uma consciência para 0 uso desses meios de comunicação.

Então, há algumas questões para se pensar: como decidir entre o que é público e/ou privado? Como utilizar as redes sociais de forma que não prejudique a mim e aos outros?

Por fim, o filme Violação de privacidade foi o pontapé inicial para a escrita deste artigo, que desencadeou as discussões elencadas posteriormente, em relação aos conceitos do que é público e privado, do que podemos ou não, se temos o direito de publicar dados, fotos e informações de outrem sem seu devido consentimento.

Responder a essas questões não foi o objetivo principal deste texto, senão colocarmo-nos a refletir a respeito, pensando de que forma orientaremos nossos filhos e estudantes, no processo de construção do conhecimento com o uso das tecnologias digitais de modo seguro e coerente. 


\section{The public and private in social networks: some reflections seconds}

\section{Zygmunt Bauman}

\section{Abstract}

This article was written from the reflections made by reading the works of sociologist Zygmunt Bauman, that were proposed in the classes doctorate. The readings were taken individually and discussions were made in group, in presential moments in the classroom and in online and distance moments, mediated by social network Facebook. The objective of this paper is to present the main ideas discussed on the concepts of what is public and private and relate them to the concept of privacy and the behavior of the digital generation in the context of social networks in cyberculture.

Keywords: Liquid modernity. Public. Private. Social networks. Cyberculture.

\section{Notas}

1 Sinopse e dados técnicos disponíveis em: <http://www.dvdpt.com/f/final_cut_a_ultima_memoria.php.> e em: <http://www.imdb.com/title/tt0364343/>. Acessos em: 12 mar. 2013.

2 Software disponível para download no endereço eletrônico: <http://cmap.ihmc.us/>. Acesso em: 12 mar. 2013.

3 Rede social disponível no endereço eletrônico: <http://www.facebook.com.>. Acesso em: 12 mar. 2013.

4 Rede social disponível no endereço eletrônico: <http://www.twitter.com>. Acesso em: 12 mar. 2013.

\section{Referências}

AGAMBEN, G. O novo êxodo. Lugar Comum, Rio de Janeiro: Ed. Fundação José Bonifácio, n. 7, jan./abril. 1999.

AGUIAR, S. Redes sociais na internet: desafios à pesquisa. In: INTERCOM - SOCIEDADE BRASILEIRA DE ESTUDOS INTERDISCIPLINARES DA COMUNICAÇÃO, CONGRESSO BRASILEIRO DE CIÊNCIAS DA COMUNICAÇÃO, 30, 2007, Santos-SP. p. 2. Disponível em: <http:// www.sitedaescola.com/downloads/portal_aluno/Maio/Redes\%20sociais\%20na\%20internet-\%20 desafios\%20\%E0\%20pesquisa.pdf $\geq$. Acesso em: 25 jul. 2012.

Produção compartilhada e socialização do conhecimento em rede: uma abordagem exploratória. In: SEMINÁRIO NACIONAL DO PROGRAMA DE PÓS-GRADUAÇÃO EM EDUCAÇÃO DA UFF - PRODUÇÃO DO CONHECIMENTO E EDUCAÇÃO: HISTÓRIA, UTOPIAS, 2, 2002. Anais... Niterói: UFF, 2002.

. Redes sociais e tecnologias digitais de informação e comunicação no Brasil (1996-2006). Relatório de pesquisa. Rio de Janeiro: Nupef, 2006.

BAUMAN, Z. Globalização: as consequências humanas. Trad. de Marcus Penchel. Rio de Janeiro: Zahar, 1999.

. Modernidade líquida. Rio de Janeiro: Jorge Zahar, 2001.

Capitalismo parasitário. Trad. de Eliana Aguiar. Rio de Janeiro: Jorge Zahar, 2010. 
Zahar, 2011.

44 cartas do mundo líquido moderno. Trad. de Vera Pereira. Rio de Janeiro: Jorge

Entrevista com o filósofo polonês Zygmunt Bauman para o Fronteiras do Pensamento. Disponível em: <http://www.youtube.com/watch?v=POZcBNo-D4A>. Acesso em: 18 jul. 2012.

CASTELLS, M. A sociedade em rede. São Paulo: Paz e Terra, 1999.

HARAWAY, D. Simians, cyborgs and women: the reinvention of nature. New York: Routledge, 1991.

LÉVY, Pierre. O que é o virtual. 9. ed. Trad. de Paulo Neves. São Paulo: Ed. 34, 2009.

MARTELETO, R. M. Redes sociais, mediação e apropriação de informações: situando campos, objetos e conceitos na pesquisa em ciência da informação. Revista Tendências da Pesquisa Brasileira em Ciência da Informação, Brasília, v. 3, n. 1, p. 27-46, jan./dez. 2010.

SANTAELLA, L. Culturas e artes do pós-humano: da cultura das mídias à cibercultura. São Paulo: Paulus, 2004.

TAPSCOTT, D. A hora da geração digital: como os jovens que cresceram usando a internet estão mudando tudo, das empresas aos governos. Trad. de Marcello Lino. Rio de Janeiro: Agir Negócios, 2010.

TUCHERMAN, I. Entre anjos e cyborgs. Revista Comunicação e Linguagens, Lisboa, v. 28, n. 1, p. 55-69, 2001.

VEIGA-NETO, A.; SARAIVA, K. Modernidade líquida, capitalismo cognitivo e educação contemporânea. Revista Educação e Realidade, Porto Alegre, v. 34, n. 2, p. 187-204, maio/ago. 2009. 